\title{
Closed Kinetic Chain Exercisee fektif Dalam Meningkatkan Kemampuan Fungsional Pada Osteoartritis Lutut
}

\author{
Faizah Abdullah Djawas ${ }^{1)}$, Wafa Rachmalillah Isna ${ }^{2)}$ \\ ${ }^{1)}$ Program Studi Fisioterapi Program Pendidikan Vokasi, Universitas Indonesia \\ Kota Depok, Jawa Barat, Indonesia \\ Phone: +62 217867222 . \\ Email : faizah.abdullah14@ui.ac.id
}

\begin{abstract}
Background:Osteoarthritis (OA) of the knee is a chronic joint disease that is characterized by abnormalities in the cartilage which will result in bones rubbing against each other, abrasion of joint cartilage and formation of osteophytes on the surface of the joints that cause symptoms such as stiffness, pain, and limitation of movement to the knee joint. Closed kinetic chain exercise (CKCE) exercise therapy generally provides benefits in reducing complaints that are expected to improve the patient's functional ability to perform activities optimally. The purpose of this study is to determine the effectiveness of closed kinetic chain exercise (CKCE) exercise methods in cases of knee osteoarthritis. Methods: A single case study, providing physiotherapy interventions for a 72-year-old woman with a diagnosis of knee OA. CKCE in the form of mini squatt movements, QSE, and step up and step down is given for 2 weeks with 4 evaluations. Pain intensity assessment using VAS, joint range of motion (ROM) assessment using goniometer, muscle strength assessment using MMT, and to assess patient functional development were measured using WOMAC parameters. Results: There was a decrease in the value of motion pain VAS at the end of the therapy session from VAS 3 to VAS 1, a decrease in pressure pain VAS value from VAS 2 to VAS 1, there was an increase in knee flexion ROM $120^{\circ}$ to $125^{\circ}$, there was an increase in MMT from 4 to 5 which was associated with WOMAC score from 37 to 26, which shows that there is an increase in the patient's functional ability by 20\% Conclusion: This study shows that the closed kinetic chain exercise (CKCE) exercise therapy method can improve functional ability in knee osteoarthritis as measured using WOMAC parameters.
\end{abstract}

Keywords : Knee Osteoarthritis, Closed Kinetic Chain Exercise, WOMAC

\begin{abstract}
ABSTRAK
Latar Belakang :Osteoartritis (OA) lutut merupakan suatu penyakit sendi menahun yang ditandai oleh adanya kelainan pada tulang rawan ( kartilago ) yang akan berakibat tulang bergesekan satu sama lain, adanya abrasi tulang rawan sendi dan pembentukan osteofit pada permukaan sendi yang menimbulkan gejala berupa kekakuan, nyeri, dan pembatasan gerakan pada sendi lutut. Terapi latihanclosed kinetic chain exercise(CKCE) umumnya memberikan manfaat dalam mengurangi keluhan yang diperkirakan mampu meningkatkan kemampuan fungsional pasien dalam melakukan aktivitas secara optimal. Tujuan dari studi ini adalah untuk mengetahui efektivitas metode latihan closed kinetic chain exercise (CKCE) pada kasus osteoartritis lutut. Metode :Studi kasus tunggal, dengan memberikan intervensi fisioterapi pada seorang wanita 72 tahun dengan diagnosis OA lutut. CKCE berupa gerakan mini squatt, QSE, dan step up and step down diberikan selama 2 minggu dengan 4 kali evaluasi. Penilaian intensitas nyeri menggunakan VAS, penilaian lingkup gerak sendi (LGS) menggunakan goniometer, penilaian kekuatan otot menggunakan MMT, serta untuk menilai perkembangan fungsional pasien dilakukan pengukuran menggunakan parameter WOMAC. Hasil : Terdapat penurunan nilai VAS nyeri gerak diakhir sesi terapi dari VAS 3 menjadi VAS 1, penurunan nilai VAS nyeri tekan dari VAS 2 menjadi VAS 1, terdapat peningkatan LGS lutut gerak fleksi $120^{0}$ menjadi $125^{\circ}$, terdapat peningkatan MMT dari 4 menjadi 5 yang dikaitkan dengan skor WOMAC dari nilai 37 menjadi 26, yang menunjukkan bahwa terdapat peningkatan terhadap kemampuan fungsional pasien sebanyak 20\%Kesimpulan:Studi ini menunjukan bahwa metode terapi latihan closed kinetic chain exercise(CKCE) dapat meningkatkan kemampuan fungsional pada osteoartritis lutut yang diukur menggunakan parameter WOMAC.
\end{abstract}

Kata Kunci : Osteoartritis lutut, Closed kinetic chain exercise, WOMAC 


\section{PENDAHULUAN}

Setiap orang akan mengalami penambahan usia dan masuk pada fase lansia. Menurut peraturan pemerintah RI Nomor 43 Tahun 2004, yang dikatakan dengan lanjut usia ( lansia ) adalah seseorang yang telah mencapai usia 60 tahun keatas. ${ }^{1}$ Ditinjau dari aspek kesehatan, lansia akan mengalami penurunan derajat kesehatan baik secara alamiah maupun akibat penyakit. Lansia yang berusia 60-70 tahun dengan lebih dari 1 diagnosis atau multi penyakit dan lansia yang berusia di atas 70 tahun yang memiliki 1 diagnosis, disertai adanya gangguan penurunan derajat fungsi organ, psikologi, sosial, ekonomi dan lingkungan disebut geriatri. ${ }^{2}$ Penurunan kesehatan yang paling sering diderita lansia yaitu golongan penyakit menlar, penyakit kronik, dan penyakit degeneratif. $^{3}$

Salah satu penyakit degeneratif yang paling banyak diderita adalah osteoartritis. Osteoartritis atau disingkat OA adalah suatu penyakit menahun yang dintandai oleh adanya kelainan pada tulang rawan (kartilago). Kartilago adalah bagian dari sendi yang melapisi ujung tulang untuk memudahkan pergerakan sendi.Kelainan pada kartilago akan berakibat tulang bergesekan satu sama lain, sehingga timbul gejala kekakuan, nyeri, dan pembatasan gerakan pada sendi. ${ }^{4}$ Kasus OA yang paling sering ditemui adalah OA lutut karena pada sendi lutut lebih sering digunakan dalam menopang tubuh. OA pada sendi lutut terjadi karena adanya abrasi pada tulang rawan dan pembentukan tulang baru (osteofit) pada permukaan sendi yang mampu menyebabkan kelemahan otot dan tendon sehingga dapat membatasi gerak dan menyebabkan nyeri. ${ }^{5}$

World Health Organization (WHO) 2019, menyebutkan bahwa OA merupakan salah satu dari sepuluh penyakit yang paling melumpuhkan di Negara maju. Perkiraan seluruh dunia adalah bahwa $9,6 \%$ pria dan $18,0 \%$ wanita berusia di atas 60 tahun memiliki OA simptomatik. $80 \%$ dari mereka yang menderita OA akan memiliki keterbatasan dalam pergerakan, dan $25 \%$ tidak dapat melakukan aktivitas hidup harian utama mereka. Sedangkan di Indonesia prevelensi OA sebanyak 11,9\% dari total penduduk Indonesia dengan angka kerjadian tertinggi pada umur $>75$ tahun yaitu sebanyak 33\%. ${ }^{6}$ Untuk OA lutut prevelensinya cukup tinggi yaitu $15,5 \%$ pada wanita dan $12,7 \%$ pada pria. ${ }^{7}$

Probelmatika fisioterapi yang ditemukan pada kondisi OA lutut yaitu, adanya nyeri pada lutut, adanya keterbatasan lingkup gerak sendi (LGS) pada lutut, adanya penurunan kemampuan fungsional, keterbatasan ambulasi, berjalan, dan melakukan aktivitas sehari- hari. ${ }^{8}$ Sehingga dibutuhkan intervensi dalam mengurangi masalah tersebut untuk meningkatkan dan mempertahankan kemandirian dalam melakukan aktivitas. Salah satunya melalui pemberian tindakan fisioterapi.

Closed Kinetic Chain Exercise (CKCE) merupakan suatu latihan gerak aktif dengan bagian distal tubuh terfiksasi, seperti telapak kaki menyentuh tanah yang melibatkan koordinasi beberapa kelompok otot dan sendi untuk meningkatkan stabilitas sendi, serta mengaktivasi proprioseptif dari telapak kaki dan gerakan latihan CKCE menyerupai gerak fungsional pada aktivitas sehari hari. ${ }^{9,10,11}$ Sehingga latihan lebih aman dan mudah dilakukan oleh pasien lansia dibandingkan dengan latihan lainnya. Latihan CKCE yang diberikan yaitu mini squatt, quadriceps setting exercise (QSE), dan setp up and step down. Penelitian sebelumnya menunjukan CKCE memberikan manfaat dalam mengurangi nyeri, melatih otot-otot tungkai bawah, meningkatkan fungsi fisik, 
meningkatkan kemampuan fungsional dan meningkatkan kualitas hidup pada penderita OA lutut. ${ }^{9}$ Oleh karena itu, studi kasus ini bertujuan untuk menilai efektivitas closed kinetic chain exercise (CKCE) terhadap penilaian kemampuan fungsional pada kasus OA lutut.

\section{TINJAUAN PUSTAKA}

\subsection{Osteoartritis Lutut}

Badan organisasi dunia (World Health Organization) WHO mendefinisikan OA sebagai penyakit kronik jangka panjang yang ditandai dengan rusaknya kartilago ( tulang rawan) sendi. Osteoartritis atau disingkat OA merupakan kelainan sendi degenerasi non inflamasi yang terjadi pada sendi yang dapat digerakan dan sendi penopang berat badan. ${ }^{4} \mathrm{OA}$ biasa terjadi pada bagian tangan, pinggang, dan lutut. Pada ekstremitas bawah OA yang sering ditemui yaitu pada sendi lutut, dengan gambaran khas memburuknya tulang rawan sendi serta terbentuknya tulang baru ( osteofit) sebagai akibat perubahan fisologis dan patologis pada tulang rawan.

Secara garis besar, terjadinya OA lutut dipengaruhi oleh dua faktor risiko, yaitu faktor predisposisi dan faktor biomekanis. Faktor predisposisi merupakan faktor yang memudahkan seseorang untuk terserang OA yaitu usia, jenis kelamin, genetik, ras atau etnis dan obesitas. Sedangkan faktor biomekanis lebih cenderung kepada faktor mekanis/ gerak tubuh yang memberikan beban atau tekanan pada sendi lutut sebagai alat gerak tubuh, seperti riwayat trauma lutut, kelainan anatomis dan aktivitas fisik sehingga meningkatkan risiko terjadinya OA. ${ }^{12}$

Manifestasi klinis yang ditampilkan OA tergantung pada sejauh mana dampak OA menyebabkan destruksi pada kartilago. Gejala OA bersifat progresif, dengan keluhan terjadi secara perlahan-lahan dan lama- kelamaan akan memburuk. Pada anamnesis kondisi klinis yang lazim didapatkan adalah sebagai berikut; persendian kaku dan nyeri, penurunan lingkup gerak sendi, krepitasi, kelemahan dan atrofi otot, deformitas, dan instabilitas sendi lutut. ${ }^{12}$

\subsection{Metode dan Teknik Intevensi}

Closed Kinetic Chain Exercise (CKCE) merupakan suatu latihan gerak aktif dengan bagian distal anggota tubuh terfiksasi, telapak kaki menyentuh tanah yang melibatkan koordinasi beberapa kelompok otot dan sendi untuk meningkatkan stabilitas sendi, serta mengaktivasi proprioseptif telapak kaki.Latihan CKCE menyerupai gerak fungsional pada aktivitas sehari- hari. , $^{90,11}$

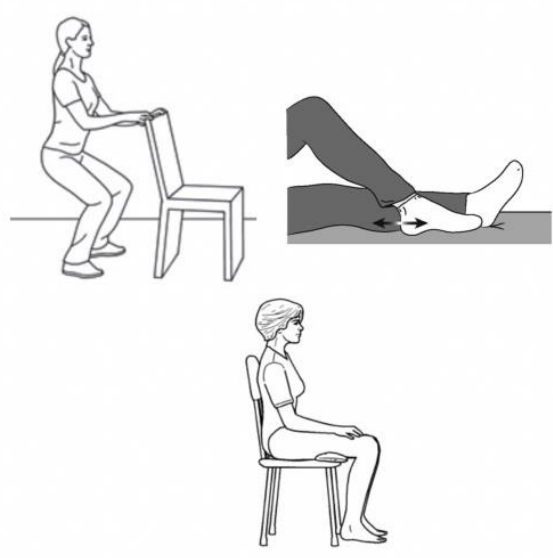

Gambar 1Gerakan terapi latihan CKCE

Pemberian latihan dengan metode terapi latihan CKCE didasari oleh kondisi pasien dan hasil dari penelitian sebelumnya yang menunjukkan CKCE lebih aman dan mudah dilakukan oleh pasien lansia dibandingkan dengan latihan lainnya. Latihan CKCE yang diberikan yaitu mini squats, quadriceps setting exercise, dan step up and step down, latihan ini bermanfaat untuk melatih otot otot tungkai bawah terutama untuk meningkatkan kemampuan fungsional pada OA lutut. 


\subsection{Pemeriksaan dan Pengukuran}

Visual Analog Scale( VAS ) adalah cara yang paling banyak digunakan untuk menilai nyeri. Skala linier ini menggambarkan secara visual gradasi tingkat nyeri yang mungkin dialami seorang pasien. Rentang nyeri diwakili sebagai garis sepanjang $10 \mathrm{~cm}$, dengan atau tanpa tanda pada tiap sentimeter. $^{13}$

MMT adalah suatu usaha untuk menentukan atau mengetahui kemampuan seseorang dalam mengkontraksikan otot atau grup otot secara volunter.Tes ini penting dilakukan pada pasien OA lutut. ${ }^{13}$

WOMAC (Western Ontario and McMaster Universities Osteoarhtritis Index) adalah indeks yang digunakan untuk menilai keadaan pasien dengan osteoartritis pada lutut.Total 24 pertanyaan yang terdiri dari nyeri, kekakuan (stiffness), fungsi fisik dan sosial dievaluasi menggunakan WOMAC. Alat ukur tersebut berupa kuisoner yang berisikan 5 pertanyaan mengenai nyeri, 2 pertanyan berhubungan dengan kekakuan sendi dan 17 pertanyan berhubungan dengan aktivitas fisik. ${ }^{14}$ Semakin rendah total nilai yang dihasilkan maka menunjukkan perbaikan pada kemampuan fungsional.

\section{METODE PENELITIAN}

Merupakan studi kasus tunggal dengan desain penelitian pre dan post test yaitu membandingkan anatara skor sebelum dan sesudah intervensi CKCE.

\subsection{Subjek}

Seorang wanitausia 72 tahun dengan diagnosis OA lutut, mengeluhkan nyeri dikedua lutut saat keberdiri dari posisi duduk dilantai. Nyeri lutut dirasakan sejak tahun 2017.Pasien kemudian melakukan pengobatan ke Rumah Sakit Umum Pusat Nasional Dr. Cipto Mangunkusumo dan dilakukan pemeriksaan ultrasonografi (USG) serta pemeriksaan X-Ray.Hasil pemeriksaan berupa osteoartritis pada lutut. Pasien kemudian menjalani fisioterapi dan penyedotan cairan di sendi lutut. Setelah dirasakan keluhan membaik, pasien lalu berhenti melakukan terapi. Keluhan kembali muncul pada 6 Januari 2020 berupa nyeri dan kaku pada lutut yang timbul saat bangun tidur, duduk keberdiri, berdiri lama mulai menit ke 20 dan berjalan jauh mulai menit ke 10. Pasien juga mengelukan kencang pada otot paha belakang dan terdengar ada bunyi di kedua lutut saat ditekuk. Nyeri berkurang saat istirahat.Untuk mengatasi keluhan saat ini, pasien menjalani fisioterapi pertama kali pada tanggal 4 Februari 2020. Kesulitan aktivitas yang dirasakan pasien saat ini adalah toileting saat jongkok (BAB dan BAK), ke berdiri dari duduk di lantai, dan saat naik turun tangga.

Subjek memiliki kesadaran compos mentis, pasien kooperatif dan cara datang pasien mandiri. Setelah dilakukan pemeriksaan umum, vital sign pasien berkesan baik, indek massa tubuh pasien overweight dan dilakukan pemeriksaan khusus pasien terdapat abnormal postur karena immbalance otot yang disebabkan oleh kebiasaan pasien saat berjalan.Pada pemeriksaan gerak fleksi lutut terdapat keterbatasan, untuk normal fleksi bernilai $135^{\circ}$, pada pasien fleksi lutut bernilai $120^{\circ}$.Dan hasil dari pemeriksaan fungsional yang dinilai menggunakan parameter WOMAC bernilai 37 yang berarti sedang.

\subsection{Waktu dan Tempat}

Penelitian dilakukan di poli fisioterapi geriatri RSUPN Dr. Cipto Mangunkusumo dan penelitian dilakukan mulai 4 Februari 14 Februari 2020.

\subsection{Penatalaksanaan Intervensi}

Intervensi berupa pemberian terapi latihan dengan metode CKCE gerakan mini squatt, QSE, dan step up and step down. Dosis latihan yang digunakan dalam setiap 
gerakan yaitu frekuensi 1x sehari, intensitas $3 x$ repetisi, dengan durasi 6 menit. Latihan dilakukan 2 kali/minggu. ${ }^{10}$

\section{HASIL DAN PEMBAHASAN}

\subsection{Hasil}

Hasil 4 kali evaluasi pemberian closed kinetic chain exercise (CKCE) selama 2 minggu pada subjek penelitian didapatkan hasil berupa :

Grafik 1 Evaluasi Skor Nyeri

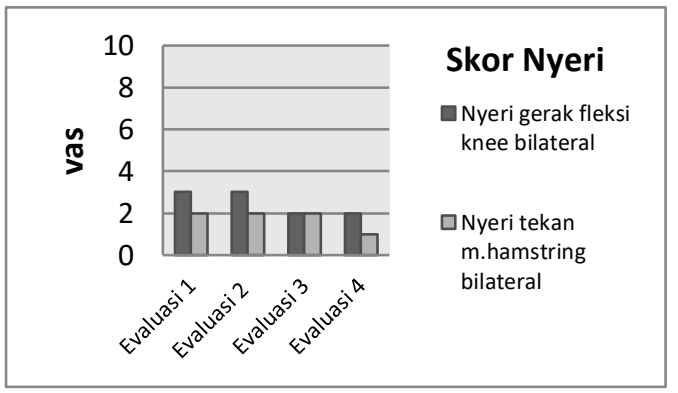

Berdasarkan grafik 1, dapat dilihat secara umum penurunan nyeri gerak dikedua lutut dan nyeri tekan pada otot hamstringyang diukur menggunakan VAS. Pada nyeri gerak, evaluasi pertama dan kedua gerak fleksi kedua lutut VAS 3 turun menjadi VAS 2 pada evaluasi ketiga dan evaluasi keempat.Dan pada nyeri tekan evaluasi pertama sampai ketiga VAS 2 turun pada evaluasi keempat menjadi VAS 1.

Grafik 2Evaluasi Skor ROM

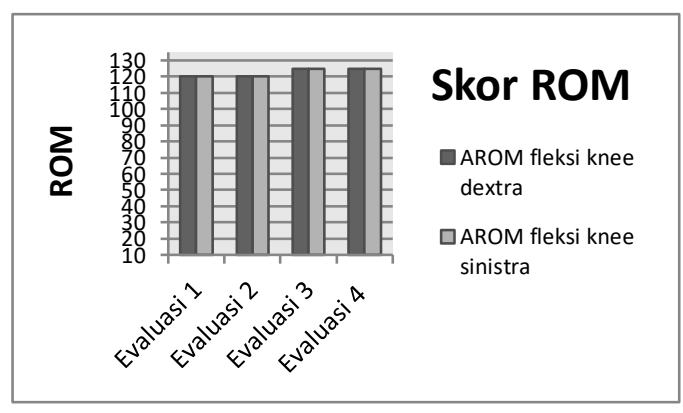

Hasil pengukuran LGS didapatkan berupa peningkatan LGS pada kedua lutut yang diukur menggunakan goniometer, pada evaluasi 1 dan evaluasi 2 AROM fleksi knee dextra dan sinistra $120^{\circ}$ menjadi $125^{\circ}$ pada evaluasi 3 dan evaluasi 4 .

Grafik 3Evaluasi Skor MMT

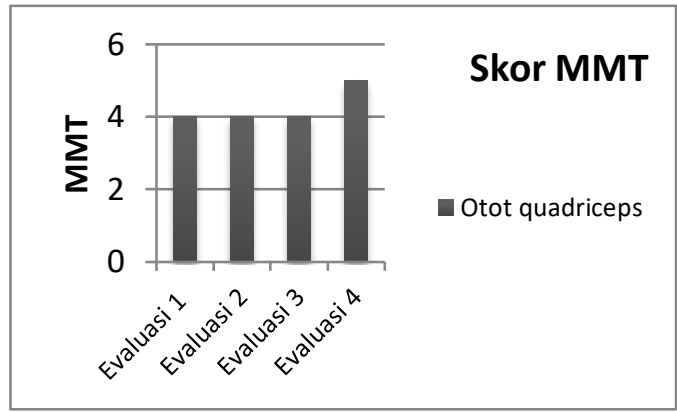

Dilihat dari grafik diatas, dari pemeriksaan kekuatan otot quadriceps yang dinilai menggunakan MMT.Didapatkan peningkatan kekuatan otot, pada evaluasi 1, 2, dan 3 MMT bernilai 4 dan pada evaluasi 4 MMT bernilai 5 .

Grafik 4Evaluasi WOMAC Skor

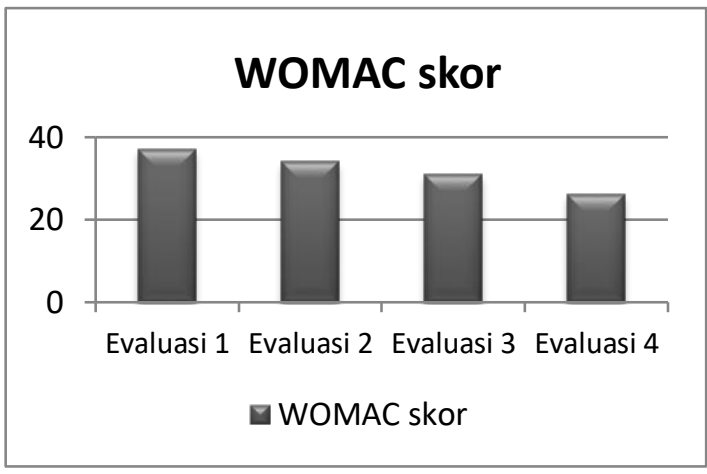

WOMAC skor pada evaluasi 137 , evluasi 2 WOMAC skor 34, evaluasi 3 WOMAC skor 31 dan pada evaluasi 4 WOMAC skor menjadi 26. Dalam hal ini membuktikan bahwa semakin kecil skor yang diperoleh pasien maka kondisi pasien semakin baik.Sehingga terjadi peningkatan dalam aktivitas fungsional pasien. 


\subsection{Pembahasan}

Penurunan nyeri yang diperoleh dari penerapan CKCE dalam studi ini didukung oleh Olagbegi OM et.al menunjukkan bahwa penguatan paha depan dapat mengaktifkan sistem $\beta$-endorphin penekan rasa nyeri, mengubah input sensorik ke pusat sistem saraf untuk mengatur persepsi nyeri dan juga meningkatkan aliran darah dan nutrisi tulang rawan. Pada penelitian tersebut yang membandingkanpada tiga kelompok intervensi OKCE, CKCE dan CCE menunjukkan efek signifikan pada average daily pain (ADP) dan pain before and after walking (PBW dan PAW) yang dievaluasi menggunakan VAS dari minggu keempat penelitian. Penelitian ini menunjukkan bahwa meskipun ketiga intervensi tersebut efektif dalam mengurangi rasa nyeri dan kecacatan pada pasien dengan OA lutut, tetapi CKCE lebih efektif daripada OKCE untuk mengurangi rasa nyeri saat berjalan. ${ }^{15}$

Studi yang dilakukan Babatunde Olusola Adegok et.al pada tahun 2019 menunjukkan bukti peningkatan LGS yang sejalan dengan hasil evaluasi pasien dalam studi ini.Setelah penerapan CKCE.Peningkatan fungsi setelah latihan penguatan paha depan, telah dikaitkan dengan peningkatan stabilitas sendi lutut yang ditingkatkan oleh peningkatan kekuatan otot, dan penguatan paha depan dapat dikaitkan dengan peningkatan aliran darah dan nutrisi pada tulang rawan. Sehingga efektif untuk meningkatkan fungsi, dan lingkup gerak sendi pada pasien OA lutut. ${ }^{9}$

Pemberikan metode terapi latihan CKCE juga meningkatkan kekuatan otot pada kedua tungkai pasien.Hal ini didukung oleh studi yang dilakukan oleh Oladapo Michael Olagbegi et.al yang menjelaskan penurunan kekuatan otot disebabkan oleh atrofi serat tipe IIB, yang bertanggung jawab untuk produksi daya yang cepat.Serat tipe
IIB menunjukkan kemampuan untuk hipertrofi setelah menjalani latihan ketegangan dan kelelahan yang tinggi.Oleh karenanya, kelemahan otot dapat diperbaiki dengan program latihan kekuatan yang tepat. Pelatihan resistensi untuk pasien OA lutut meningkatkan kekuatan otot lebih dari 50$75 \%$ dari studi kohort yang ditinjau, juga efek positif dan negatif dari latihan resistensi progresif (PRE) mengidentifikasi peningkatan kekuatan pembentukan kapasitas otot sebagai manfaat dari PRE pada pasien. Latihan esensi yang juga telah dideskripsikan, merupakan metode yang valid untuk meningkatkan kemampuan otot. ${ }^{9}$

Perubahan yang terjadi pada ketiga parameter tersebut secara tidak langsung diyakini meningkatkan kemampuan fungsional pasien yang dinilai menggunakan parameter WOMAC.Caleb Ademola Gbiri et.al pada tahun 2013 menunjukkan hasil bahwa pemberian latihan membuktikan interaksi antara kekuatan otot dan propriosepsi dalam peningkatan kemampuan fungsional. Selain itu, OKCE dan CKCE dinilai dapat meningkatkan kinerja fungsional dan mengurangi gejala serta keparahan pada individu dengan OA lutut. ${ }^{16}$

\section{KESIMPULAN}

Metode terapi latihan closed kinetic chain exercise (CKCE) dinilai efektif dalam meningkatkan kemampuan fungsional pada pasien osteoartritis (OA) lutut yang dinilai menggunakan parameter WOMAC.

\section{REFERENSI}

1. Perundang-undangan BP, Hukum B. Peraturan Pemerintah Republik Indonesia Nomor 43 Tahun 2004 Tentang Pelaksanaan Upaya Peningkatan Kesejahteraan Sosial Lanjut Usia Presiden. Peratur Pemerintah Republik Indones Nomor 43 Tahun 2004. 2004;1- 
17.

2. President of the Republic of Indonesia. Government's Regulation No. 79/2014 on National Energy Policy. 2014;5. Available from: https://www.hukumonline.com/pusatdata /downloadfile/lt545b3735a66b4/parent/lt $545 \mathrm{~b} 36 \mathrm{c} 00 \mathrm{c} 94 \mathrm{f}$

3. Kemenkes RI. Analisis Lansia di Indonesia. Pus data dan Inf Kementeri Kesehat RI [Internet]. 2017;1-2. Available from: www.depkes.go.id/download.php?file $=\mathrm{d}$ ownload/.../infodatin lansia 2016.pdf\%0A

4. Wiarto. Nyeri Tulang dan Sendi. Gosyeng Publishing; 2017.

5. Yatim.F. Penyakit Tulang dan Persendian ( Arthritis atau Arthralgia ). Jakarta: Pustaka Populer Obor; 2006.

6. Dasar RK. Penyajian Pokok-Pokok Hasil Riset Kesehatan Dasar 2013. 2013;

7. Lespasio MJ, Piuzzi NS, Husni ME, Muschler GF, Guarino A, Mont MA. Knee Osteoarthritis: A Primer. Perm J. 2017;21:1-7.

8. Purnomo D, Abidin Z, Wicaksono RD. Pengaruh Micro Wave Diathermy Dan Terapi Latihan Pada Osteoarthritis Genu. J Fisioter dan Rehabil. 2017;1(2):10-7.

9. Adegoke BO, Sanya AO, Ogunlade SO, Olagbegi OM. The effectiveness of open versus closed kinetic chain exercises on pain, function and range of motion in patients with knee osteoarthritis. Balt $\mathbf{J}$ Heal Phys Act. 2019;11(3):39-52.

10. Susilawati I, Tirtayasa K, Lesmana I. Sport and Fitness Journal. Latih Closed Kinet Chain Lebih Baik Daripada Open Kinet Chain untuk Meningkatan Kemamp Fungsional Pada Osteoarthr Lutut Setelah Pemberian MWD dan TENS. 2015;3(1):26-34.

11. Kwon YJ, Park SJ, Jefferson J, Kim K. The effect of open and closed kinetic chain exercises on dynamic balance ability of normal healthy adults. J Phys Ther Sci. 2013;25(6):671-4.

12. Heidari B. Knee osteoarthritis prevalence, risk factors, pathogenesis and features: Part I. Casp J Intern Med.
2011;2(2):205-12.

13. Norkin CC WD. Measurement of Joint Motion A Guide to Goniometry. 4th ed. Philadelphia; 2009.

14. Osteoarthritis M, Womac I. Western Ontario and McMaster Universities Osteoarthritis Index. Handb Dis Burdens Qual Life Meas. 2010;1433:4352-4352.

15. Om O, Boa A. Corresponds to : Oladapo Michael Olagbegi , Principal Physiotherapist, Federal Medical Centre , Owo, Ondo State, Nigeria , E-mail : olagbegioladapo@yahoo.com. 15(02).

16. AdemolaGbiri C, Okafor UAC. Comparative Efficacy of Open-chain and Close-chain Kinematics on Proprioception, Muscles Strength and Functional Performances in Individual with Knee Osteoarthritis. Occup Med Heal Aff. 2013;01(01):1-5.

Wafa Rachmalillah, memperoleh Ahli Madya Fisioterapi pada tahun 2020 di Universitas Indonesia

Faizah Abdullah, memperoleh gelar Ahli Madya Fisioterapi pada tahun 2010 dari Program D-III Fisioterapi Fakultas Kedokteran Universitas Indonesia. Kemudian pada tahun 2012 memperoleh gelar Sarjana Sain Terapan Fisioterapi dari Fakultas Fisioterapi Universitas Esa Unggul.Tahun 2017 mendapatkan gelar Magister Ilmu Biomekanik dari Program Megister Ilmu Biomekanik, Fakultas Kedokteran Universitas Indonesia.Saat ini bekerja sebagai Dosen Tetap Program Studi Fisioterapi Program Vokasi Universitas Indonesia. 